\title{
Identification of Alternaria Species Causing Heart Rot of Pomegranates in California
}

Y. Luo, L. Hou, and H. Förster, Department of Plant Pathology and Microbiology, University of California, Riverside 92521; B. Pryor, School of Plant Sciences, University of Arizona, Tucson 85721; and J. E. Adaskaveg, Department of Plant Pathology and Microbiology, University of California, Riverside

\begin{abstract}
Alternaria heart rot of pomegranate fruit is generally considered a minor disease. However, the current listing of the causal pathogen in California as "Alternaria sp." or as "A. alternata and other Alternaria spp." restricts trade of the crop to some major export markets where quarantines are in place in an effort to prevent the spread of unknown or undescribed pathogens. Thus, species identification of the pathogen is critical in determining whether infected fruit should be regulated by quarantines. In this study, 86 isolates of Alternaria were collected from pomegranate fruit with Alternaria heart rot symptoms from major production areas in California. An unweighted pair group method with arithmetic means analysis based on amplified fragment length polymorphisms revealed two main clusters, each with a high degree of variability. One of the clusters contained 24 isolates from pomegranate and one reference isolate of Alternaria arborescens. Reference isolates of A. alternata and A. tenuissima were found among pomegranate isolates in the other cluster, and these two species could not be separated. In maximum-parsimony

analysis of ribosomal DNA internal transcribed spacer sequence data, representative pomegranate isolates all clustered with reference sequences of species in section Alternaria. Single-nucleotide differences separated A. arborescens, A. gaisen, and two pomegranate isolates from the majority of the remaining isolates. Sequence comparisons of gapdh and OPA10-2 loci indicated that none of the pomegranate isolates were identical to A. gaisen, which is a quarantine pathogen. Due to high genetic similarity and variability of morphological characteristics, revisions of the taxonomy of small-spored Alternaria spp. have been proposed by others. Based on this recent taxonomic work and work herein by us, pomegranate isolates from California can be assigned to A. alternata and A. arborescens. Reassessment of export restrictions for California pomegranate due to the previous pathogen classification is warranted. Fruit injection inoculations with conidia of 12 representative isolates 3 months before harvest caused typical symptoms of Alternaria heart rot, whereas flower inoculations did not result in fruit disease.
\end{abstract}

Pomegranate (Punica granatum L.) is considered to have originated in central Asia, and the crop has been cultivated since ancient times (Erkan and Kader 2011). Today, the fruit is grown worldwide in semiarid to subtropical climates. Major production areas include India, Central Asia, the United States, southern Europe, the Middle East, the Caucasus region, North Africa, and the drier parts of Southeast Asia. In California, the pomegranate production area in the southern San Joaquin Valley has expanded from 5,000 ha in 2006 to 11,300 ha in 2014, predominantly growing 'Wonderful' pomegranate (Anonymous 2014). This increase was prompted by consumer demand for the highly nutritious crop that is consumed as fresh fruit, extracted arils, and juice products. A large portion of the harvested crop in California is exported, mainly to Southeast Asian countries.

Pomegranate fruit are affected by relatively few diseases. The most important fruit decay worldwide is gray mold, caused by Botrytis cinerea Pers. (Erkan and Kader 2011; Romanazzi et al. 2016; Tedford et al. 2005). Alternaria heart rot, also called black heart or Alternaria rot, is generally of more minor importance. Another fruit rot, caused by Aspergillus niger Tiegh., has also been called black heart but currently is referred to as Aspergillus fruit rot (Adaskaveg and Michailides 2011). In California, Alternaria heart rot incidence has increased with increased production in recent years (Day and Wilkins 2011; Michailides et al. 2008), ranging between 0 and $6 \%$. Alternaria heart rot has also been reported in Greece (Tziros et al. 2007), Cyprus (Bardas et al. 2009; Kahramanoglu et al. 2014; Kanetis et al. 2015), Turkey (Pala et al. 2009), Israel (Ezra et al. 2015), India (Benagi et al. 2011), and Spain (Vicent et al. 2016), and the pathogens have been variously described as Alternaria alternata (Fr.) Keissl., A. arborescens E. G. Simmons, A. tenuissima (Kunze) Wiltshire, Alternaria sp., or Alternaria spp. Similarly, in California, the causal agents of Alternaria heart rot were identified as Alternaria sp. (French 1989; LaRue 1977; Smoot et al.

Corresponding author: J. E. Adaskaveg; E-mail: jim.adaskaveg@ucr.edu

Accepted for publication 30 October 2016.

C 2017 The American Phytopathological Society
1971) or as A. alternata and other Alternaria spp. (Michailides et al. 2008), based on morphological characteristics. Airborne spores of the pathogen are thought to cause infections of flowers during bloom (Ezra et al. 2015; Michailides et al. 2008). Infections may remain latent for most of the growing season before active internal decay is initiated. In some cases, diseased fruit in the field or after harvest can be identified by abnormal skin color and light weight (Zhang and McCarthy 2012; Ezra et al. 2015). Fruit often drop before harvest and, thus, harvesting practices include shaking of trees before picking fruit. Internally, the fruit shows brown to black decay of the arils and connective tissues (Fig. 1A). Sporulation of the pathogen may occur on decayed tissues. Because diseased fruit are difficult to identify at harvest based on external symptoms, detection methods using nuclear magnetic resonance relaxometry and magnetic resonance imaging have been developed (Zhang and McCarthy 2012).

The current listing of the Alternaria heart rot pathogens in California as "A. alternata and Alternaria sp." restricts trade to some major export markets where quarantines are in place in an effort to prevent the spread of unknown or undescribed species. Our preliminary microscopic examination of isolates indicated that they belong to the small-spored Alternaria spp. Proper identification of the pathogen or pathogens is critical for all issues related to disease epidemiology and management. Moreover, revision of trade quarantine restrictions may allow removal of "Alternaria sp." from international quarantines of California pomegranates and, thus, allow free trade. Therefore, determining the species causing Alternaria heart rot of pomegranate in California is critical for the pomegranate industry.

Historically, identification of Alternaria spp. has been based on morphological characteristics, including cultural morphology, size and shape of conidia, and branching patterns of conidial chains (Simmons 1999, 2007; Simmons and Roberts 1992). Although major Alternaria sections can be differentiated using these characteristics, the high degree of variability observed makes this approach difficult, especially when closely related species need to be identified (Andrew et al. 2009; Armitage et al. 2015). The production of host-specific toxins has been used to distinguish some species (Kusaba and Tsuge 1995) but this proved to be unreliable because toxin production was sometimes spontaneously lost in certain strains (Johnson et al. 2001). Molecular approaches based on 
analyses of ribosomal DNA (rDNA) sequences have supported the broad morphological taxonomic categories within the genus Alternaria (Peever et al. 2004; Pryor and Bigelow 2003; Pryor and Gilbertson 2000). However, poor resolution, even when more variable genetic loci were investigated for the small-spored taxa within the section Alternaria (i.e., A. alternata, A. tenuissima, A. arborescens, A. mali Roberts, and A. gaisen Nagano ex Hara) created much debate as to which species should be maintained. It was suggested that $A$. alternata and A. tenuissima should be combined (Andrew et al. 2009; Woudenberg et al. 2015) or that the latter two species and A. arborescens should be merged into a single species, A. alternata (Armitage et al. 2015).

The objective of this study was to identify Alternaria spp. causing heart rot of pomegranate fruit in California. An unambiguous species assignment will clarify the pathogen's quarantine status and, therefore, may alleviate current trade restrictions that include specific harvesting and packing protocols to ensure that diseased fruit are not exported. Isolates from the major pomegranate-growing areas were initially grouped by amplified fragment length polymorphisms (AFLP). Selected isolates were then used for sequence analyses of three loci in comparison with representative small-spored Alternaria spp. in the section Alternaria.

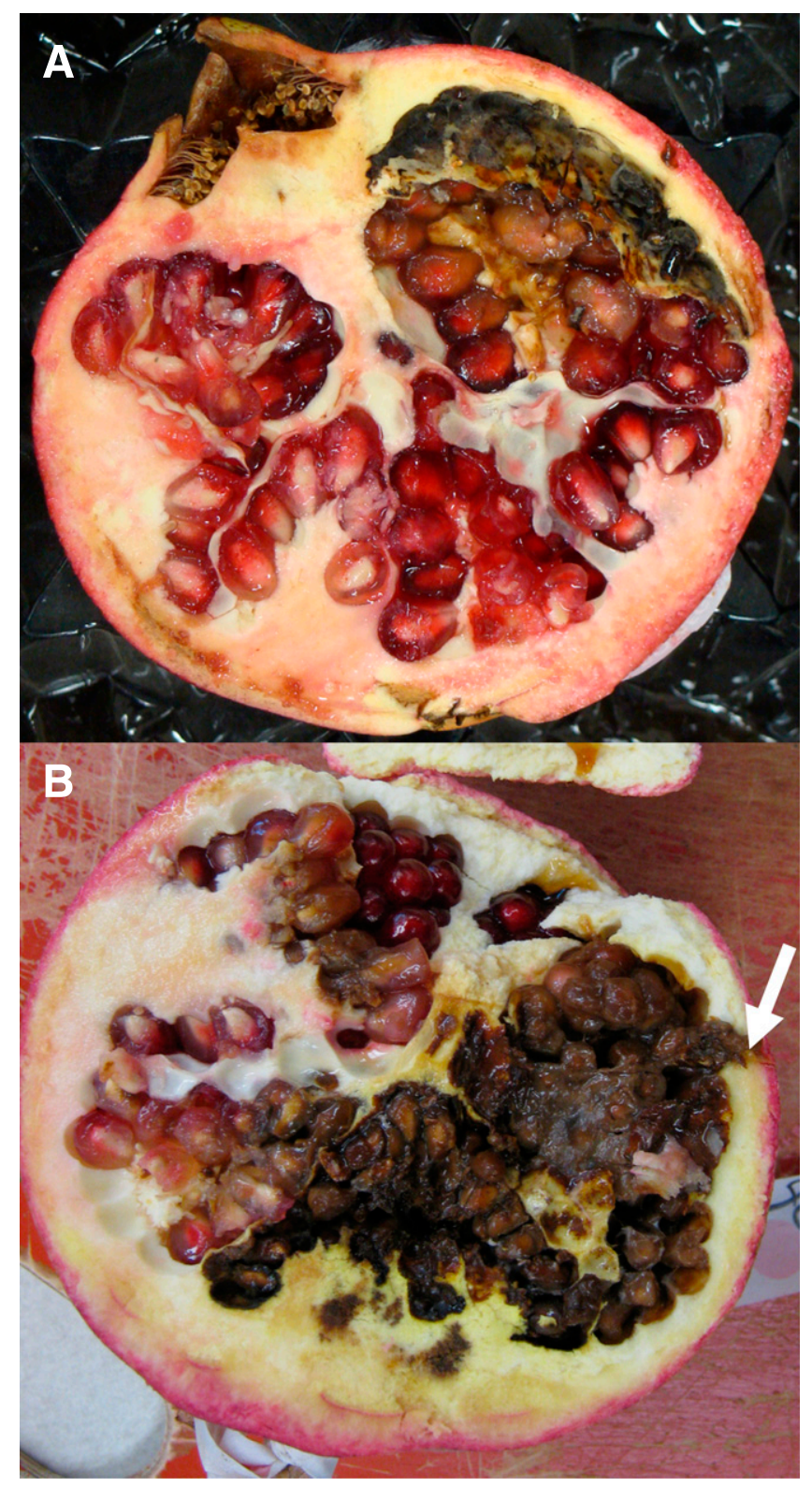

Fig. 1. Symptoms of Alternaria heart rot of pomegranate. A, Natural infection and B, symptoms after inoculation of fruit by injection of a conidial suspension of Alternaria alternata. The injection site is indicated by an arrow.

\section{Materials and Methods}

Fungal isolations and growth conditions. Pomegranate fruit with suspected Alternaria heart rot (i.e., discolored fruit with light weight) were collected between 2008 and 2013 in six packinghouses in the Central Valley of California (Fresno, Tulare, and Kern Counties) that together process over $90 \%$ of the commercial pomegranate crop of the state. Fruit were cut open with a sterilized knife, and diseased arils were plated onto potato dextrose agar (PDA; Difco Laboratories, Detroit) amended with rifampicin (Sigma-Aldrich, St. Louis) at $20 \mathrm{mg} / \mathrm{liter}$ and ampicillin (Sigma-Aldrich) at $130 \mathrm{mg} /$ liter. Plates were incubated at $25^{\circ} \mathrm{C}$. Hyphal tip cultures of isolated fungi were grown on nonamended PDA and Alternaria spp. were identified based on cultural characteristics and morphology of 25 conidia for each isolate. Reference cultures for the AFLP analysis were included for A. alternata (EGS 34-039), A. arborescens (EGS 39-128), and A. tenuissima (EGS 34-015). Isolates JEA 1967 (alt), BMP 0630 (arb), and BMP 0508 (ten) from almond and pistachio in California were added that were identified to species in previous publications (Pryor and Michailides 2002; Teviotdale et al. 2001).

DNA extraction. Isolates were grown on PDA at $25^{\circ} \mathrm{C}$ for 7 days. Conidia and hyphal fragments of each isolate were collected into an extraction tube by scraping an agar area of approximately $2 \mathrm{~cm}^{2}$ with a sterile spatula. For DNA extraction, the FastDNA SPIN kit for soil (MP Biomedicals LLC, Solon, OH) was used. DNA preparations were resuspended in sterile distilled water and adjusted to $50 \mathrm{ng} / \mu \mathrm{l}$.

AFLP procedures and data analysis. AFLP reactions were performed using a modified protocol by Vos et al. (1995). The restriction-ligation reaction contained approximately $50 \mathrm{ng}$ of genomic DNA, $5 \mathrm{U}$ of EcoRI, $1 \mathrm{U}$ of $M s e \mathrm{I}, 20 \mathrm{U}$ of T4 DNA ligase (all enzymes from New England BioLabs, Ipswich, MA), $5 \mu \mathrm{M}$ EcoR1 adapter mix in Tris-EDTA (TE; $10 \mathrm{mM}$ Tris $+1 \mathrm{mM}$ EDTA at $\mathrm{pH}$ 8.0), $50 \mu \mathrm{M}$ MseI adapter mix in TE, $1 \times$ ligase buffer, $5 \mu \mathrm{g}$ of bovine serum albumin, and $50 \mathrm{mM} \mathrm{NaCl}$ in a final volume of $11 \mu \mathrm{l}$. After incubation at $37^{\circ} \mathrm{C}$ for 2 to $2.5 \mathrm{~h}, 90 \mu \mathrm{l}$ of $\mathrm{TE}_{0.1}(10 \mathrm{mM}$ Tris and $0.1 \mathrm{mM}$ EDTA, $\mathrm{pH} 8$ ) was added and the reaction was stored at $4^{\circ} \mathrm{C}$. Amplifications were done in a final volume of $12.5 \mu \mathrm{lusing}$ $1.5 \mu \mathrm{l}$ of the diluted digestion-ligation reaction, $200 \mu \mathrm{M}$ each dNTP, $0.8 \mu \mathrm{M}$ Mse primer, $0.16 \mu \mathrm{M}$ 6-carboxyhexachlorofluorescein (HEX)- or 6-carboxyfluorescein (FAM)-labeled EcoRI primer, $1 \mu \mathrm{g}$ of bovine serum albumin, $1 \times$ Taq polymerase buffer, and $0.75 \mathrm{U}$ of Taq DNA polymerase (New England BioLabs). Sixteen primer pairs were initially screened for amplification. Four primer pairs were then chosen for analysis based on repeatability and easily distinguishable polymorphic bands: (i) MseI (5'-GACGAT GAGTCCTGAGTA)-TC-3'/EcoR1 (5'-GACTGCGTACCAATTC) FAM-AC-3', (ii) MseI-AC-3'/EcoR1-HEX-TA-3', (iii) MseI-TT-3'/ EcoR1-FAM-CA-3', and (iv) MseI-GC-3'/EcoR1-HEX-TA-3'.

Polymerase chain reaction (PCR) conditions comprised an initial denaturation at $94^{\circ} \mathrm{C}$ for $2 \mathrm{~min}$; followed by a touchdown phase of $13 \mathrm{cy}-$ cles of $94^{\circ} \mathrm{C}$ for $30 \mathrm{~s}, 65^{\circ} \mathrm{C}$ for $30 \mathrm{~s}$, and $72^{\circ} \mathrm{C}$ for $60 \mathrm{~s}$, lowering the annealing temperature by $0.7^{\circ} \mathrm{C}$ at each successive cycle; followed by 23 cycles of $94^{\circ} \mathrm{C}$ for $30 \mathrm{~s}, 56^{\circ} \mathrm{C}$ for $30 \mathrm{~s}$, and $72^{\circ} \mathrm{C}$ for $60 \mathrm{~s}$; and a final extension step of $72^{\circ} \mathrm{C}$ for $5 \mathrm{~min}$. Aliquots of $0.5 \mu \mathrm{l}$ of PCR were mixed with $0.125 \mu$ l of GeneScan-500 LIZ size standard (Applied Biosystems, Carlsbad, CA) and denatured with $9.875 \mu \mathrm{l} \mathrm{Hi}-$ Dye formamide (Applied Biosystems) in a total volume of $11 \mu \mathrm{l}$ for 3 min at $94^{\circ} \mathrm{C}$. AFLP fragments were separated with an ABI 3100 genetic analyzer (Applied Biosystems) and analyzed using the GeneScan software (Applied Biosystems). To validate reproducibility of the procedure, each AFLP reaction run included one or several "standard" isolates and the analysis was performed at least twice for each isolate.

GeneScan AFLP data files were imported into Genographer software (version 2.1; http://genographer.software.informer.com/2.1/) for visual analysis. AFLP profiles were analyzed in the 80- to 300-bp size range on a virtual gel. Consistent fragments that were shared by at least two individuals and that had band intensities greater than $85 \mathrm{U}$ were used for analysis. Fragments were considered individual loci that were either present (a scoring of 1) or absent (a scoring of 0), and a binary data matrix was created. Genetic similarities based on Dice coefficients for pairs of isolates were calculated using SIMQUAL of the 
NTSYSpc software (ver. 2.21c) (Rohlf 2009), and clustering was done using the unweighted pair group method with arithmetic means (UPGMA). To determine how well the UPGMA dendrogram represented the original similarity matrix, a matrix of cophenetic values was generated using the COPH program in NTSYS-pc, and the MXCOMP program was used to calculate the level of correlation between the cophenetic matrices and the original similarity matrix.

DNA sequencing and sequence analysis. Isolates representing different clusters of the AFLP dendrogram (Fig. 2) were selected for sequencing. The nuclear rDNA internal transcribed spacer (ITS) region, including ITS 1 and 2 and the 5.8S ribosomal gene, and the gapdh locus were amplified using primers ITS5 and ITS4 (White et al. 1990) and gpd1 and gpd2 (Berbee et al. 1999), respectively. The OPA10-2 locus was amplified for isolates JEA 3859, JEA 3883, and JEA 3939 using primers OPA10-2 L and OPA10-2R (Andrew et al. 2009). PCR in a total volume of $25 \mu \mathrm{l}$ contained the following: $10 \mathrm{ng}$ of DNA, $12.5 \mu \mathrm{l}$ of PCR master mix (Promega Corp., Madison, WI), and $0.25 \mathrm{mM}$ each primer. Reaction conditions were $95^{\circ} \mathrm{C}$ for $3 \mathrm{~min}$; followed by 39 cycles of $94^{\circ} \mathrm{C}$ for $30 \mathrm{~s}, 58^{\circ} \mathrm{C}$ (ITS region), $54^{\circ} \mathrm{C}$ (gapdh), or $62^{\circ} \mathrm{C}$ (OPA10-2) for $30 \mathrm{~s}$, and $72^{\circ} \mathrm{C}$ for $30 \mathrm{~s}$; followed by an additional 5-min extension at $72^{\circ} \mathrm{C}$. PCR products were purified using ExoSAP-IT (Affymetrix, Inc., Santa Clara, CA) and sequences were determined with an ABI PRISM 377 DNA Sequencer using Big Dye Terminator chemistry (Perkin-Elmer/ABI, Foster City, CA). Primers used for sequencing were the same as for amplification and sequences of both strands were determined for each isolate.

For the ITS region and gapdh, sequences of the pomegranate isolates and of representative isolates of Alternaria spp. in sections Alternaria, Sonchi, Radicina, Panax, and Porri (Table 1) were aligned using MacClade Phylogenetic Software (version 3.05; Sinauer Associates, Sunderland, MA). In some cases, manual adjustments of sequence alignments were performed using the data editor program of MacClade. Phylogenetic analyses were performed using PAUP (version 4.0 beta). For maximum-parsimony (MP) analysis, heuristic searches were conducted using random step-wise additions of 1,000 replicates and branch swapping by tree bisection-reconnection. Sequence gaps were recoded and were treated as a fifth character. For statistical analyses of resolved trees, 1,000 nonparametric bootstrap replicates were performed under the MP criteria and a bootstrap consensus tree was constructed. For evaluation of OPA10-2 sequences, pairwise comparisons were performed using the BLAST function in the National Center for Biotechnology Information (http://www. ncbi.nlm.nih.gov/), and percent identity values are reported.

Pathogenicity tests. Four Alternaria isolates from pomegranate (i.e., JEA 3873, JEA 3883, JEA 3906, and JEA 3916) were used for flower inoculations of Wonderful pomegranate at field locations at the University of California-Davis, Davis, and at the University of California Kearney Agricultural Research and Extension Center (KARE), Parlier, CA, in May 2013. Conidial suspensions $\left(2 \times 10^{5}\right.$ conidia/ml $)$ were sprayed to run-off into the floral tube of 15 flowers on each of four trees for each isolate. This was performed in the evening to ensure that flowers would stay wet for some time. As the fruit matured, they were evaluated for disease development. For Wonderful pomegranate fruit inoculations in the field at KARE in July 2012 and 2013, 12 isolates of Alternaria representing different clusters of the AFLP dendrogram (Fig. 2) were used. Conidial suspensions ( $5 \mathrm{ml}$ of $2 \times 10^{5}$ spores $/ \mathrm{ml}$ ) were injected with a syringe to a depth of $2 \mathrm{~cm}$ into an equatorial area in relation to the crown of each of five fruit for each isolate. Control fruit were injected with sterile water. Two weeks prior to the commercial harvest date for Wonderful pomegranate (mid-October), inoculated fruit were cut open with a knife and evaluated for decay. Alternaria heart rot symptoms were verified by the presence of Alternaria conidia or by reisolation and cultural characteristics of the isolated fungi. Alternaria heart rot incidence was then calculated based on the total number of inoculated fruit. The experiment was performed twice.

\section{Results}

AFLP analysis of Alternaria sp. isolates from pomegranate. AFLP fingerprinting analysis was conducted for 86 isolates of Alternaria sp. that were obtained from pomegranate fruit with Alternaria heart rot symptoms and for reference isolates of A. alternata,
A. arborescens, and A. tenuissima. In total, 78 polymorphic bands that were generated by four primer pairs were used for compiling a data set. Neighbor-joining analysis revealed a high degree of diversity among isolates (Fig. 2). Haplotypes were shared by no more than 2 isolates, the majority of isolates clustered closely in groups of 4 to 11 isolates, and only 2 isolates had unique fragment patterns. Two major clusters were identified: one contained 24 isolates from pomegranate and a reference isolate of A. arborescens; the other contained the remaining pomegranate isolates and reference isolates of A. alternata and A. tenuissima, and the latter two species could not be separated.

Sequence analysis of the rDNA ITS, gapdh, and OPA10-2 regions. Thirteen isolates from pomegranate were selected from the analysis of AFLP data representing different clusters of the dendrogram. Reference sequences of small-spored Alternaria spp. (i.e., species in section Alternaria) and of species belonging to four other established sections of the genus were included in the analysis. The MP tree separated the sections within the genus with high support values (Fig. 3). All of the pomegranate isolates clustered within section Alternaria, and isolates were identical except for single-nucleotide differences. Reference sequences of A. arborescens and A. gaisen and those of pomegranate isolates JEA 3859 and JEA 3883 showed a single base deletion, and sequences of pomegranate isolates JEA 3878 and JEA 3944 had a single base (A-C) transversion compared with the other sequences.

A similar clear separation of Alternaria sections was also obtained by analysis of gapdh sequences (Fig. 4), confirming that this locus is taxonomically informative. Pomegranate isolates JEA 3876 and JEA 3939 that clustered with $A$. alternata and A. tenuissima and isolates JEA 3859 and JEA 3883 that were identical to A. arborescens and A. gaisen in the ITS analysis (Fig. 3) grouped with several species of section Alternaria but were distinct from A. gaisen (Fig. 4). A sequence comparison of the OPA10-2 locus confirmed that pomegranate isolates JEA 3859 and JEA 3883 were closer to A. arborescens than to A. gaisen (Table 2).

Pathogenicity tests. None of the flower inoculations resulted in Alternaria heart rot disease of pomegranate fruit. Instead, most of the inoculated flowers dropped within 1 week after inoculation. Inoculated fruit were evaluated for the presence of Alternaria heart rot symptoms 10 to 12 weeks after inoculation. Although several fruit dropped prematurely, typical internal symptoms with blackened arils developed for all 12 isolates used and, thus, all were confirmed to be pathogenic on pomegranate (Fig. 1B). Muriform-septate spores typical of Alternaria spp. were often present on infected arils and the pathogen was successfully reisolated. The average incidence of Alternaria heart rot for the isolates used in the two experiments conducted was 30\% (isolate JEA 3870), 40\% (isolates JEA 3859 and JEA 3864), 60\% (isolates JEA 3891 and JEA 3939), 70\% (isolate JEA 3916), 80\% (isolates JEA 3873, JEA 3883, JEA 3937, JEA 3977 , and JEA 3936), or 100\% (isolate JEA 3906).

\section{Discussion}

In this study, isolates of Alternaria spp. causing Alternaria heart rot of pomegranate fruit in California were determined to belong to two clades in the small-spored section Alternaria. AFLP analysis of 86 isolates identified numerous polymorphisms that allowed a preliminary grouping. The reference isolate of $A$. arborescens and an additional isolate previously identified as this species were found among pomegranate isolates within a distinct cluster. Reference and previously identified isolates of A. alternata and A. tenuissima were within another cluster but could not be separated. Although AFLP data are not suitable for phylogenetic analysis, the close relationship between the latter two species is in agreement with studies by others using several loci (Andrew et al. 2009; Armitage et al. 2015; Rotondo et al. 2012). Our subsequent sequence analysis of the rDNA ITS and gapdh regions further support the taxonomic assignment of the pomegranate isolates in section Alternaria.

The taxonomy and identification of small-spored Alternaria spp. has been notoriously difficult and often controversial. Simmons (1999) assigned A. alternata, A. arborescens, A. gaisen, A. limoniasperae E. G. Simmons, A. longipes (Ellis \& Everh.) E. W. Mason, A. mali, A. tenuissima, and A. toxicogenica E. G. Simmons to a group of 
host-specific toxin producers. He strongly argued against merging them into a single taxon, A. alternata, as proposed by Nishimura and Kohmoto (1983) and Kusaba and Tsuge (1995). Simmons stated that these species are distinguishable taxa that exhibit discrete morphological identities when cultured under specific conditions. This concept was again challenged with the use of molecular taxonomic methods that employed an ever-increasing number of putative, highly variable genetic loci in sequence analyses. Thus, Andrew et al.

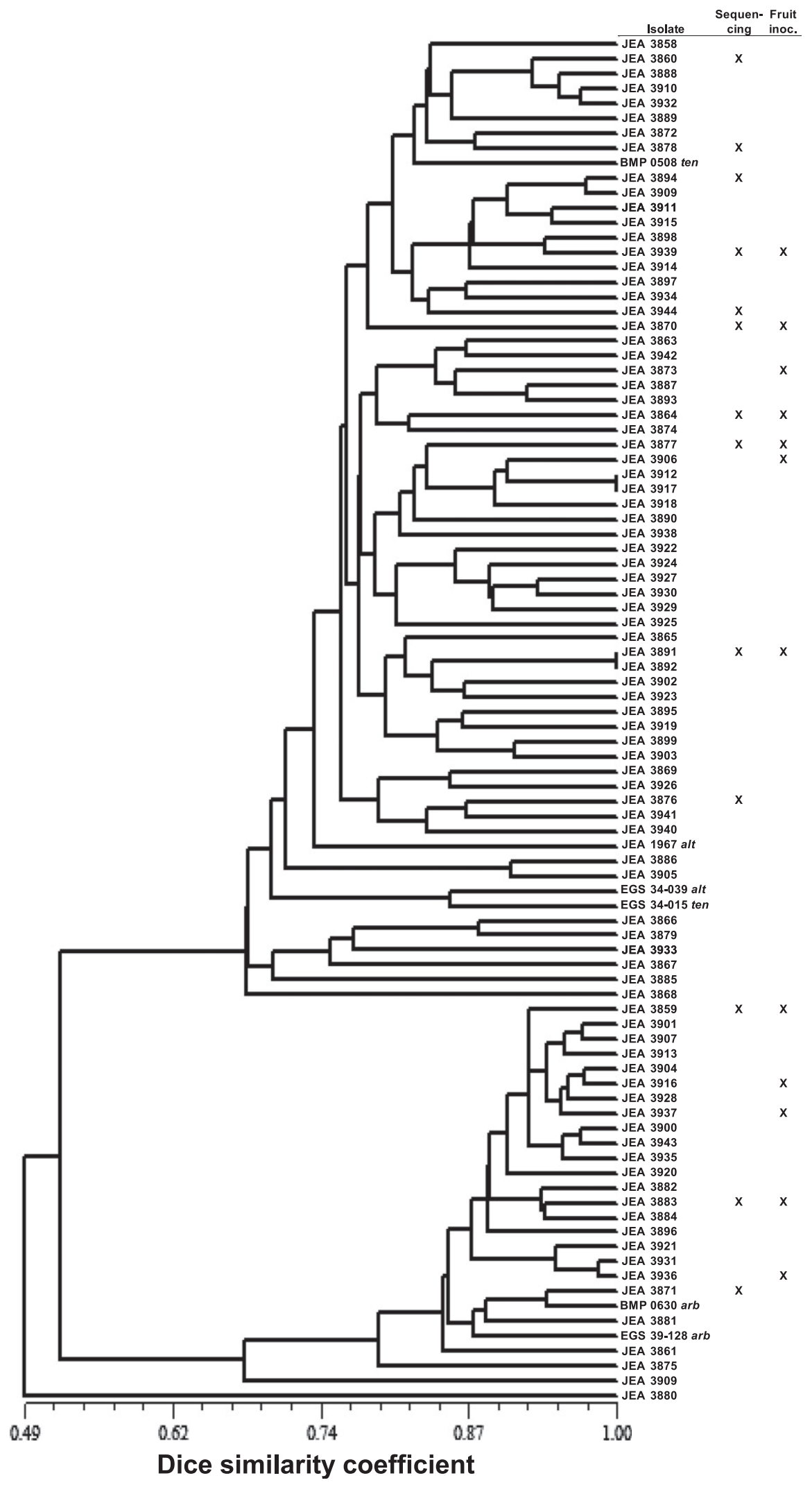

Fig. 2. Dendrogram based on the unweighted pair group method with arithmetic means (UPGMA) constructed from a binary database of amplified fragment length polymorphisms from 86 isolates of Alternaria from pomegranate in California. Reference isolates of Alternaria alternata (alt), A. arborescens (arb), and A. tenuissima (ten) have the EGS prefix, whereas isolates JEA 1967 (alt), BMP 0630 (arb), and BMP 0508 (ten) were identified to species in previous publications (Pryor and Michailides 2002; Teviotdale et al. 2001). Phylogenetic relationships are not represented. Only isolates that were used in sequence analyses or fruit inoculations are identified by their accession number. Matrix correlation of the UPGMA analysis $r=0.9458$. 
(2009) concluded that morphological classification was a poor predictor of phylogenetic lineage among small-spored Alternaria taxa. Because only A. arborescens could be separated, they proposed a phylogenetic $A$. arborescens group and suggested that all other isolates should be referred to as A. alternata until more information

Table 1. Alternaria reference sequences used for phylogenetic analyses in this study, their sources, and GenBank accession numbers

\begin{tabular}{llllc}
\hline & & \multicolumn{3}{c}{ GenBank accession } \\
\cline { 3 - 5 } Species & \multicolumn{1}{c}{ Source $^{\mathbf{a}}$} & ITS $^{\mathbf{b}}$ & gapdh & OPA10-2 \\
\hline Alternaria alternata & EGS 34-016 & AF347031 & AY278808 & JQ859828 \\
A. arborescens & EGS 39-128 & AF347033 & AY278810 & JQ859830 \\
A. cinerariae & EGS 33-169 & AY154700 & AY562413 & $\ldots$ \\
A. dauci & ATCC 36613 & AF229466 & AY278803 & $\ldots$ \\
A. destruens & EGS 46-069 & AY278836 & AY278812 & $\ldots$ \\
A. eryngii & EGS 41-005 & JQ693661 & Y562416 & $\ldots$ \\
A. gaisen & EGS 90-0512 & JX397905 & JQ646317 & EF504047 \\
A. limoniasperae & EGS 45-100 & FJ266476 & AY562411 & $\ldots$ \\
A. longipes & EGS 30-033 & AY278835 & AY278811 & $\ldots$ \\
A. panax & EGS 29-180 & JQ693662 & JQ646299 & $\ldots$ \\
A. petroselini & EGS 09-159 & AF229454 & AY278799 & $\ldots$ \\
A. radicina & ATCC 96831 & AF229472 & AY278797 & $\ldots$ \\
A. solani & ATCC 58177 & AF229475 & AY278807 & $\ldots$ \\
A. sonchi & EGS 46-051 & JN383484 & AY562412 & $\ldots$ \\
A. tenuissima & EGS 34-015 & AF347032 & Y278809 & JQ859829 \\
\hline
\end{tabular}

a Abbreviations for source are as follows: ATCC $=$ American Type Culture Collection, Manassas, VA 20108 and EGS = E. G. Simmons, Mycological Services, Crawfordsville, IN 47933.

b Internal transcribed spacer. could be gathered. Similar results were obtained in another morphological and sequence-based study with isolates from apple, where only isolates assigned to the A. arborescens morphogroup formed a distinct cluster in the phylogenetic sequence analyses, not those in the A. alternata and A. tenuissima morphogroups (Rotondo et al. 2012). In another recent taxonomic study of section Alternaria, relationships were elucidated based on morphological comparisons and sequence analyses of five loci, including three newly identified highly variable ones with a total of 237 parsimonious-informative sites (Armitage et al. 2015). Three major phylogenetic lineages were identified. Representatives of $A$. arborescens and a reference isolate of $A$. gaisen were each found in a single lineage, whereas isolates of A. tenuissima, A. alternata, and A. mali were present in a third lineage. Morphological analyses by the authors supported the separation of $A$. arborescens, but $A$. tenuissima, A. alternata, and A. mali could not be differentiated. The authors of this study concluded that morphological characteristics obtained from a single culture are too variable to be practical for identification. Because these species have highly conserved sequences for the barcoding locus ITS (Pryor and Michailides 2002), Armitage et al. (2015) proposed that the three phylogenetic lineages identified represent diverging subspecies (i.e., subspp. arborescens, tenuissima, and gaisen) within a single species, A. alternata. Still, a different taxonomic scheme for section Alternaria was recently suggested by Woudenberg et al. (2015) based on sequence analyses of seven loci. These authors propose combining 35 morphospecies, including A. tenuissima, under A. alternata because they could not be separated in their analyses. A. arborescens, however, is conserved as a taxon, and numerous closely related, previously recognized taxa are combined in an A. arborescens species complex. Therefore, there is agreement that $A$. tenuissima cannot be maintained

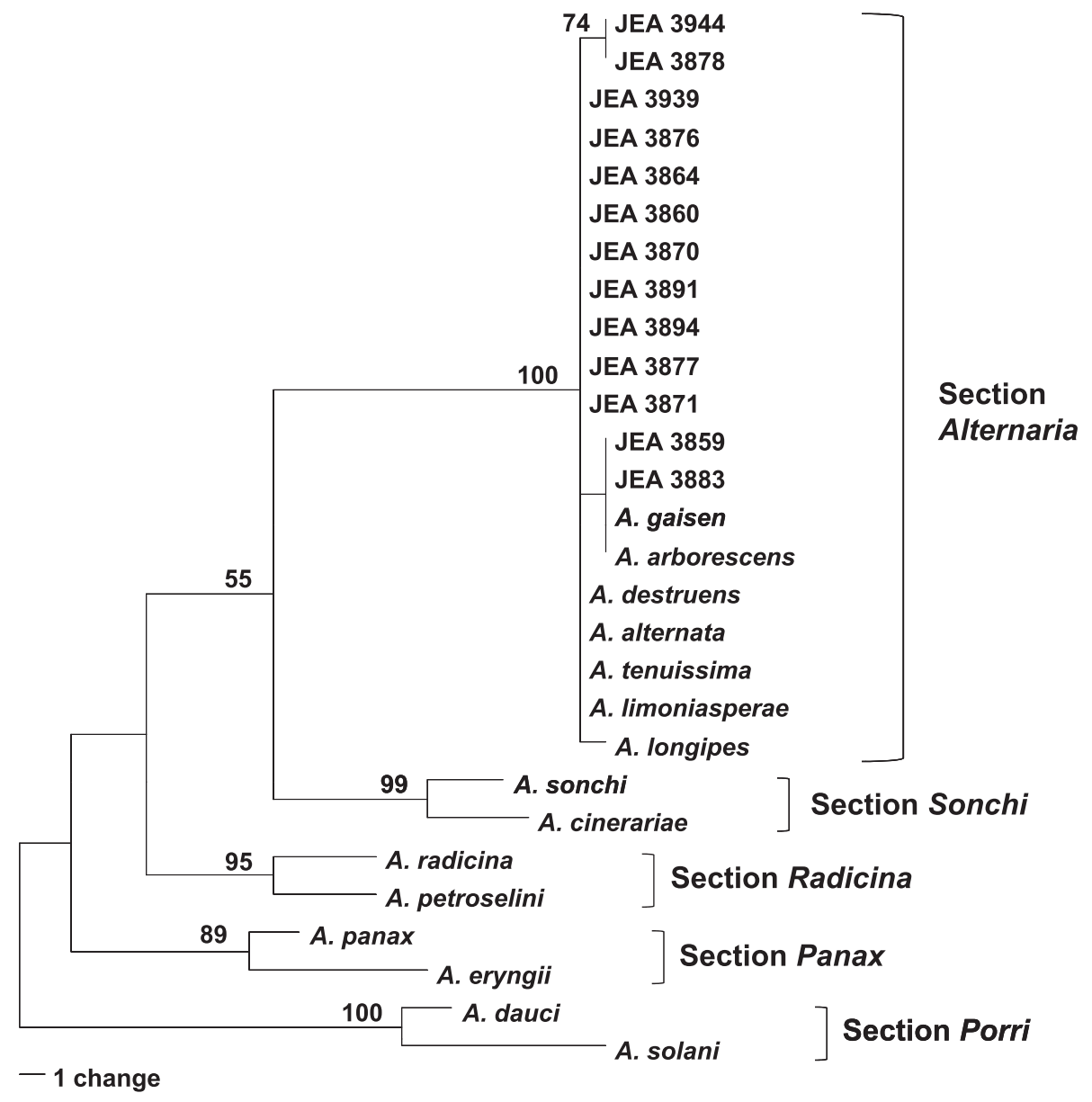

Fig. 3. One of three most-parsimonious trees generated from maximum-parsimony analysis of internal transcribed spacer sequences. Steps $=92$; consistency index $=0.837$; retention index $=0.899$. Numbers at each node represent parsimony bootstrap values from 1,000 bootstrap replicates. Nodes without values were less than $70 \%$. All Alternaria spp. isolates used are listed in Table 1; other isolates are JEA collection numbers. 
as a species; however, further revisions of the taxonomy of smallspored Alternaria spp. will likely be made in the future.

In a recent study on Alternaria fruit rot of pomegranate from Greece and Cyprus, the causal decay fungi were identified as A. alternata, A. tenusisima, and A. arborescens based on endoPG sequences and morphological characteristics, including sporulation patterns (Kanetis et al. 2015). As described above, we were not able to separate A. alternata from A. tenuissima. In characterizing Alternaria isolates from blueberry in California, Zhu and Xiao (2015) also follow the traditional classification of small-spored Alternaria spp. These authors maintain that $A$. alternata, A. tenuissima, and A. arborescens can be clearly separated by sequence analysis of the plasma membrane ATPase gene. Their phylogenetic tree indicates several groups with high bootstrap values, among them an A. arborescens cluster that contained three reference sequences. Only one reference sequence of A. alternata (EGS 34-016) was included in their analysis, and this was placed in the A. alternata cluster. Only one of the seven A. tenuissima reference sequences, however, was placed in the A. tenuissima cluster, whereas two of the sequences grouped with $A$. alternata and four sequences were not assigned to a major species cluster. Therefore, this study does not support molecular separation of the three small-spored Alternaria spp. and, instead, adds to the growing evidence that these taxa cannot be clearly separated. Blueberry (Zhu and Xiao 2015), pomegranate, and other hosts such as pistachio (Pryor and Michailides 2002) and almond (Teviotdale et al. 2001) are affected by Alternaria diseases. Because of the overlapping production areas of these crops in the Central Valley of California and the overall ubiquitous occurrence of Alternaria spp. decaying organic material, populations of the pathogen are likely to disseminate among these hosts.

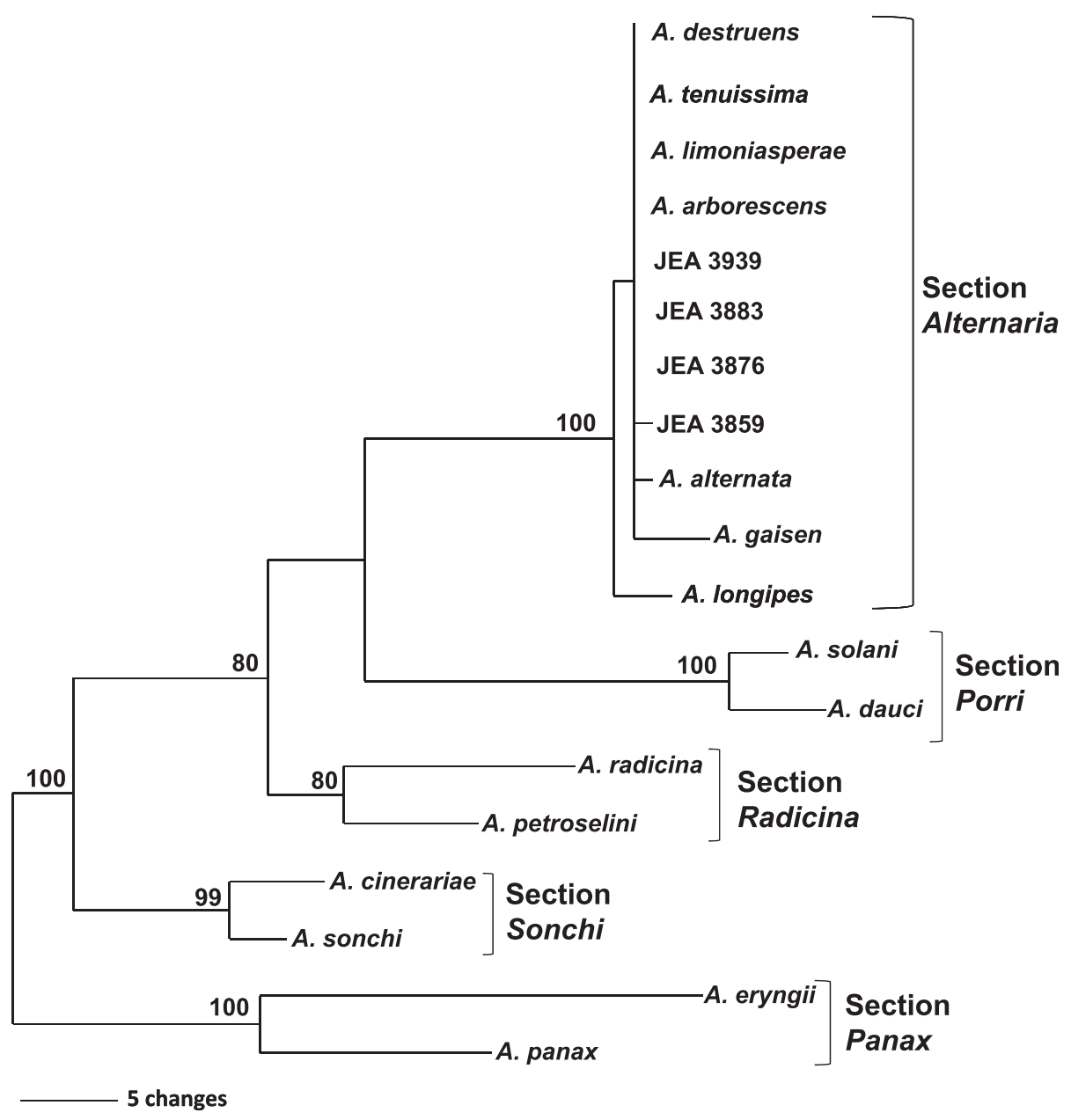

Fig. 4. Single most-parsimonious tree generated from maximum-parsimony analysis of gapdh sequences. Steps $=155$; consistency index $=0.858$; retention index $=0.888$. Numbers at each node represent parsimony bootstrap values from 1,000 bootstrap replicates. Nodes without values were less than $70 \%$. All Alternaria spp. isolates used are listed in Table 1; other isolates are JEA collection numbers.

Table 2. Pairwise comparison of OPA10-2 sequences of selected pomegranate isolates and Alternaria reference species ${ }^{\mathrm{a}}$

\begin{tabular}{|c|c|c|c|c|c|c|c|}
\hline Species or isolate & Alternaria alternata & A. arborescens & A. gaisen & A. tenuissima & JEA 3939 & JEA 3859 & JEA 3883 \\
\hline Alternaria alternata & 100 & 97 & 97 & 99 & 100 & 96 & 96 \\
\hline A. arborescens & 97 & 100 & 96 & 97 & 97 & 99 & 99 \\
\hline A. gaisen & 97 & 96 & 100 & 97 & 97 & 96 & 95 \\
\hline A. tenuissima & 99 & 97 & 97 & 100 & 99 & 96 & 96 \\
\hline JEA 3939 & 100 & 97 & 97 & 99 & 100 & 96 & 96 \\
\hline JEA 3859 & 96 & 99 & 96 & 96 & 96 & 100 & 99 \\
\hline JEA 3883 & 96 & 99 & 95 & 96 & 96 & 99 & 100 \\
\hline
\end{tabular}

a Pairwise comparisons were performed using the BLAST function in the National Center for Biotechnology Information (http://www.ncbi.nlm.nih.gov/), and percent identity values are reported. Data in bold show $\geq 99 \%$ similarity. 
In our study, most of the isolates from pomegranate included in the ITS sequence analysis were identical to $A$. alternata reference sequence EGS 34-039 (as well as to sequences of A. tenuissima, A. destruens, and A. limoniaspora); whereas others were indistinguishable from A. arborescens and A. gaisen, or differed by a single base-pair substitution. Sequence analyses of additional loci that were recommended for separation of small-spored Alternaria spp. by Woudenberg et al. (2015) indicated that pomegranate isolates cannot be assigned to A. gaisen. Thus, based on the most recent taxonomy, we conclude that the pathogens causing Alternaria heart rot of pomegranate in California are A. alternata and A. arborescens. These often opportunistic plant pathogens are ubiquitous organisms and are not in the United States Department of Agriculture Phytosanitary Export Database of Harmful Organisms for California's main trading partners of agricultural commodities. Therefore, reassessment of export restrictions for California pomegranate fruit due to the previous classification of the Alternaria pathogen as "Alternaria sp." or as "A. alternata and other Alternaria spp." is warranted.

Twelve representative Alternaria isolates from pomegranate were found to be pathogenic to pomegranate, and typical symptoms of Alternaria heart rot developed when fruit were injected with conidia approximately 3 months before harvest. Nonwound spray inoculations of fruit or wound inoculation of fruit at a later maturation stage were not successful (data not presented). Although natural infections are thought to originate at flowering time, our flower inoculations also did not result in fruit disease. Therefore, infection time and site for these pathogens warrant further investigation. Potentially, insect injuries may be sites of entry for the Alternaria pathogens, and Alternaria fruit rot may be a stigmatomycosis similar to dry rot caused by Nematospora coryli Peglion (Fawcett 1929). For inoculation of pomegranate fruit, we selected isolates from widely separated clusters of the AFLP dendrogram and there was no evidence for a pomegranate-specific group of isolates. Host adaptation in specific lineages, however, may be present for isolates infecting other crops (Armitage et al. 2015).

\section{Acknowledgments}

We thank D. Felts and D. Cary, University of California, Riverside, Kearney Agricultural Research and Extension Center, for helping to collect Alternaria isolates from regulatory sample submissions of pomegranate fruit.

\section{Literature Cited}

Adaskaveg, J. E., and T. J.Michailides, T. J. 2011. Pomegranate-Alternaria fruit rot. UC IPM Pest Management Guidelines: Pomegranate UC ANR Publication 3474.

Andrew, M., Peever, T. L., and Pryor, B. M. 2009. An expanded multilocus phylogeny does not resolve morphological species within the small-spored Alternaria species complex. Mycologia 101:95-109.

Anonymous. 2014. California county agricultural commissioners' reports. https:// www.nass.usda.gov/Statistics_by_State/California/Publications/AgComm/

Armitage, A. D., Barbara, D. J., Harrison, R. J., Lane, C. R., Sreenivasaprasad, S., Woodhall, J. W., and Clarkson, J. P. 2015. Discrete lineages within Alternaria alternata species group: Identification using new highly variable loci and support from morphological characters. Fungal Biol. 119:994-1006.

Bardas, G. A., Tzelepis, G. D., Lotos, L., and Karaoglanidis, G. S. 2009. First report of Botrytis cinerea causing gray mold of pomegranate (Punica granatum) in Greece. Plant Dis. 93:1346.

Benagi, V. I., Ravi Kumar, M. R., Gowdar, S. B., and Pawar, B. B. 2011. Survey on diseases of pomegranate in Northern Karnataka, India. Acta Hortic. 890:509-511.

Berbee, M. L., Pirseyedi, M., and Hubbard, S. 1999. Cochliobolus phylogenetics and the origin of known, highly virulent pathogens, inferred from ITS and glyceraldehyde-3-phosphate dehydrogenase gene sequences. Mycologia 91: 964-977.

Day, K. R., and Wilkins, E. D. 2011. Commercial pomegranate (Punica granatum L.) production in California. Acta Hortic. 890:275-285.

Erkan, M., and Kader, A. A. 2011. Pomegranate (Punica granatum L.). Pages 287-311, 312e-313e in: Postharvest Biology and Technology of Tropical and Subtropical Fruits, Vol. 4. E. M. Yahia, ed. Woodhead Publishing Ltd., Oxford.

Ezra, D., Kirshner, B., Hershcovich, M., Shtienberg, D., and Kosto, I. 2015. Heart rot of pomegranate: Disease etiology and the events leading to development of symptoms. Plant Dis. 99:496-501.

Fawcett, H. S. 1929. Nematospora on pomegranates, citrus and cotton in California. Phytopathology 19:479-482.

French, A. M. 1989. California Plant Disease Host Index. Department of Food and Agriculture, Sacramento, CA.
Johnson, L. J., Johnson, R. D., Akamatsu, H., Salamiah, A., Otani, H., Kohmoto, K., and Kodama, M. 2001. Spontaneous loss of a conditionally dispensable chromosome from the Alternaria alternata apple pathotype leads to loss of toxin production and pathogenicity. Curr. Genet. 40:65-72

Kahramanoglu, I., Usanmaz, S., and Nizam, I. 2014. Incidence of heart rot at pomegranate fruits caused by Alternaria spp. in Cyprus. Afr. J. Agric. Res. 9:905-907.

Kanetis, L., Testempasis, S., Goulas, V., Samuel, S., Myresiotis, C., and Karaoglanidis, G. S. 2015. Identification and mycotoxigenic capacity of fungi associated with preand postharvest fruit rots of pomegranates in Greece and Cyprus. Int. J. Food Microbiol. 208:84-92.

Kusaba, M., and Tsuge, T. 1995. Phylogeny of Alternaria fungi known to produce host-specific toxins on the basis of variation in internal transcribed spacers of ribosomal DNA. Curr. Genet. 28:491-498.

LaRue, J. H. 1977. Growing pomegranates in California. Pamphlet 2459. University of California, Division of Agricultural Science, Oakland, CA.

Michailides, T., Morgan, D., Quist, M., and Reyes, H. 2008. Infection of pomegranate by Alternaria spp. causing black heart. (Abstr.) Phytopathology 98:S105.

Nishimura, S., and Kohmoto, K. 1983. Host-specific toxins and chemical structures from Alternaria species. Annu. Rev. Phytopathol. 21:87-116.

Pala, H., Tatli, A., Yilmaz, C., and Özgüven, A. I. 2009. Important diseases of pomegranate fruit and control possibilities in Turkey. Proc. 1st International Symposium on Pomegranate and Minor Mediterranean Fruits. Acta Hortic. 818:285-290.

Peever, T. L., Su, G., Carpenter-Boggs, L., and Timmer, L. W. 2004. Molecular systematics of citrus-associated Alternaria species. Mycologia 96:119-134.

Pryor, B. M., and Bigelow, D. M. 2003. Molecular characterization of Embellisia and Nimbya species and their relationship to Alternaria, Ulocladium and Stemphylium. Mycologia 95:1141-1154.

Pryor, B. M., and Gilbertson, R. L. 2000. Molecular phylogenetic relationships amongst Alternaria species and related fungi based upon analysis of nuclear ITS and mt SSU rDNA sequences. Mycol. Res. 104:1312-1321.

Pryor, B. M., and Michailides, T. J. 2002. Morphological, pathogenic, and molecular characterization of Alternaria isolates associated with Alternaria late blight of pistachio. Phytopathology 92:406-416.

Rohlf, F. J. 2009. NTSYSpc: Numerical Taxonomy System. ver. 2.21c. Exeter Software, Setauket, NY.

Romanazzi, G., Smilanick, J. L., Feliziani, E., and Droby, S. 2016. Integrated management of postharvest gray mold on fruit crops. Postharvest Biol. Technol. 113:69-76.

Rotondo, F., Collina, M., Brunelli, A., and Pryor, B. M. 2012. Comparison of Alternaria spp. collected in Italy from apple with A. mali and other AM-toxin producing strains. Phytopathology 102:1130-1142.

Simmons, E. G. 1999. Alternaria themes and variations (236-243). Host-specific toxin producers. Mycotaxon 70:325-369.

Simmons, E. G. 2007. Alternaria: An Identification Manual. CBS Fungal Biodiversity Centre, Utrecht, The Netherlands.

Simmons, E. G., and Roberts, R. G. 1992. Alternaria themes and variations (73). Mycotaxon 48:109-140.

Smoot, J. J., Houck, L. G., and Johnson, H. B. 1971. Market Diseases of Citrus and Other Subtropical Fruits. Agric. Handb. No. 398. United States Department of Agriculture, Washington, DC

Tedford, E. C., Adaskaveg, J. E., and Ott, A. J. 2005. Impact of Scholar (a new post-harvest fungicide) on the California pomegranate industry. Online publication. Plant Health Prog. doi:10.1094/PHP-2005-0216-01-PS

Teviotdale, B. L., Viveros, M., Pryor, B., and Adaskaveg, J. E. 2001. First report of Alternaria leaf spot of almond caused by species in the Alternaria alternata complex in California. Plant Dis. 85:558.

Tziros, G. T., Lagopodi, A. L., and Tzavella-Klonari, K. 2007. Alternaria alternata fruit rot of pomegranate (Punica granatum) in Greece. New Dis. Rep. 15:14. http://www.ndrs.org.uk/article.php?file=2007-20.asp

Vicent, A., Mira, J. L., Bartual, J., Beltrán, V., Taberner, V., and Palou, L. 2016. First report of black heart of pomegranate caused by Alternaria alternata in Spain. Plant Dis. 100:1952.

Vos, P., Hogers, R., Bleeker, M., Reijans, M., Lee, T., Van de Hornes, M., Frijters, A. Pot, J., Peleman, J., Kuiper, M., and Zabeau, M. 1995. AFLP: A new technique for DNA fingerprinting. Nucleic Acids Res. 23:4407-4414.

White, T. J., Bruns, T., Lee, S., and Taylor, J. 1990. Amplification and direct sequencing of fungal ribosomal RNA genes for phylogenetics. Pages 315-322 in: PCR Protocols: A Guide to Methods and Applications. M. A. Innis, D. H. Gelfand, J. J. Sninsky, and T. J. White, eds. Academic Press, San Diego, CA.

Woudenberg, J. H. C., Seidl, M. F., Groenewald, J. Z., de Vries, M., Stielow, J. B., Thomma, B. P. H. J., and Crous, P. W. 2015. Alternaria section Alternaria: Species, formae speciales or pathotypes. Stud. Mycol. 82:1-21.

Zhang, L., and McCarthy, M. J. 2012. Black heart characterization and detection in pomegranate using NMR relaxometry and MR imaging. Postharvest Biol. Technol. 67:96-101.

Zhu, X. Q., and Xiao, C. L. 2015. Phylogenetic, morphological, and pathogenic characterization of Alternaria species associated with fruit rot of blueberry in California. Phytopathology 105:1555-1567. 